\title{
Open Surgical Repair of Retrocaval Ureter Without Excision of Retrocaval Segment: Results of 8 Cases in a Single-Center
}

\section{Retrokaval Segmentin Eksizyonu Olmadan Retrokaval Üreterde Açı Cerrahi Onarım: Tek-Merkezdeki 8 Olgunun Sonucu}

\author{
Fuat Kızılay, Serdar Kalemci, Adnan Şimşir, Bülent Semerci
}

Ege Üniversitesi Tıp Fakültesi, Üroloji Ana Bilim Dalı, İzmir

Dergiye Ulaşma Tarihi: 27.11.2018 Dergiye Kabul Tarihi:30.01.2019 Doi: 10.5505/aot.2019.95866

\section{ÖZET}

GİRIŞ ve AMAÇ: Retrokaval üreter (RÜ), üreterin vena kavanın posteriorundan geçmesiyle karakterize, oldukça nadir görülen bir konjenital anomalidir. Retrokaval segmentin eksizyonu olmadan açık cerrahi onarım ile tedavi ettiğimiz 8 olgunun verilerini sunmayı amaçladık.

YÖNTEM ve GEREÇLER: 2005-2018 yılları arasında kliniğimizde RÜ tanısı ile opere edilen 8 hasta çalışmaya dahil edildi. Hastaların demografik verileri, peri- ve postoperatif verileri hasta dosyalarından kaydedildi ve değerlendirildi. Ayrıca hastalara uygulanan görüntüleme yöntemleri kaydedildi. Dinamik sintigrafideki $\mathrm{T}^{1} 12$ değerinin pre- ve postoperatif değerleri karşılaştırıldı. Tüm hastalara açık yöntemle retrokaval segmentin eksizyonu olmadan üreteroüreteral anostomoz uygulandı. İstatistiksel analiz için SPSS 22.0 kullanıldı ve p değerinin 0.05 'den küçük değerleri, istatistiksel olarak anlamlı kabul edildi.

BULGULAR: Hastaların 5'i erkek, 3'ü kadındı. Ortalama yaş 36.2 yıldı (25-48). Ortalama operasyon süresi 64 dakikaydı (58-92). Altı hastada (\%75) başvuru yakınması yan ağrısıydı. Ortalama hastanede yatış süresi 2.32 gündü. Postoperatif dönemde tüm hastalara kontrol amacıyla bilgisayarlı tomografi-ürografi ve nükleer tıp çalışması ile dinamik ve statik renal sintigrafi uygulandı. Hastaların preoperatif ve postoperatif statik sintigrafileri arasında istatistiksel anlamlı bir ilişki yoktu $(\mathrm{p}=0.741)$ ancak, dinamik renal sintigrafi farklılığı anlamlıd 1 (preoperatif ortalama $\mathrm{T}^{1} / 2$ değeri $25.7 \mathrm{dk}$, postoperatif ortalama $\mathrm{T}^{1} 12$ değeri ise $14.4 \mathrm{dk}, \mathrm{p}=0.016$ ).

TARTIŞMA ve SONUÇ: Retrokaval segmentte eksizyon yapılmaksızın retrokaval üretere uygulanan reanostomoz, minimal postoperatif morbidite, kısa hastanede kalış süresi ile başarılı sonuçlar sağlamaktadır.

Anahtar Kelimeler: Rtrokaval üreter, üreteroüreteral anostomoz, üreteral obstrüksiyon, renal sintigrafi

\begin{abstract}
INTRODUCTION: Retrocaval ureter (RU) is a rare congenital anomaly characterized by the passage of the ureter through the posterior of the vena cava. We aimed to present the data of 8 cases treated with open surgical repair without excision of the retrocaval segment.

METHODS: Eight patients who were operated with the diagnosis of RU in our clinic between 2005-2018 were included in the study. Demographic data, peri- and postoperative data of the patients were recorded and evaluated. In addition, imaging modalities were recorded. Pre- and postoperative values of $\mathrm{T}^{1} / 2$ values in dynamic scintigraphy were compared. All patients underwent open ureterouretereral anostomosis without excision of the retrocaval segment. SPSS 22.0 was used for statistical analysis and p values less than 0.05 were considered statistically significant.

RESULTS: Five patients were male and 3 were female. The mean age was 36.2 years (25-48). The mean operation time was 64 minutes (58-92). Six patients (75\%) presented with flank pain. The mean hospitalization duration was 2.32 days. In the postoperative period, all patients underwent computed tomography-urography and dynamic and static renal scintigraphy with nuclear medicine study. There was no statistically significant difference between preoperative and postoperative static scintigraphy values $(\mathrm{p}=0.741)$, but dynamic renal scintigraphy difference was significant $\left(\mathrm{T}^{1} / 2\right.$ was $25.7 \mathrm{~min}$. preoperatively and $14.4 \mathrm{~min}$. postoperatively, $\mathrm{p}=$ 0.016).

DISCUSSION AND CONCLUSION: Re-anostomosis performed for the retrocaval ureter without any excision of the retrocaval segment yields successful results with minimal postoperative morbidity and short hospital stay. Keywords: retrocaval ureter, uretero-ureteral anostomosis, ureteral obstruction, renal scintigraphy
\end{abstract}




\section{GİRIŞ}

Sirkumkaval üreter veya preüreteral vena kava olarak da adlandırılan retrokaval üreter (RÜ), üreterin vena kavanın posteriorundan geçmesiyle karakterize, oldukça nadir görülen bir konjenital anomalidir. Bu anomalinin neden olduğu ciddi fonksiyonel obstrüksiyon durumunda, cerrahi onarım kaçınılmazdır. Standart cerrahi onarım, retrokaval segmentin eksizyonu ile üreteroüreteral veya üreteropelvik re-anostomoz ile yer değiştirmesini içerir (1). Cerrahi onarım, açık, laparoskopik veya robotik yöntemle uygulanabilir. Cerrahın tecrübesi, mevcut ekipman, hastanın özellikleri ve tercihi, bu kararda belirleyici faktörlerdir.

RÜ, genellikle sağ tarafta görülmekle birlikte nadiren sol tarafta, situs inversus veya inferior vena kava (IVK) anomalileri-sol IVK veya IVK duplikasyonu ile birlikte görülebilir. RÜ prevalansı otopsi serilerinde 1/1.500 olarak gösterilmiştir ve erkeklerde daha sıktır (2). RÜ, IVK'nin posteromedialinden aşağı doğru yol alır, önünden lateraline doğru geçer ve normal seyrine dönerek distal olarak mesaneye doğru devam eder. Konjenital bir anomali olmasina rağmen, hastalar genellikle 3 . veya 4 . dekada kadar asemptomatiktir. Renal pelvis ve proksimal üreter tipik olarak elonge ve dilatedir ve vena kavanın arkasından geçmeden önce J veya balık-oltası şeklindedir (3). Semptomların kaynağı vena kava ve psoas kasının arasında sıkışan üreter segmentinin yol açtığ1 proksimal hidroüreteronefroza bağl1 flank ağrı, piyelonefrit ve taş oluşumu gibi komplikasyonlardır. Tanısı, ekskretuar ürografi ile değerlendirilebilir ve helikal bilgisayarlı tomografi ile konfirme edilebilir. Bu patoloji ilk zamanlarda bir üreter gelişim anomalisi olarak düşünülmüştür ancak, bazı embriyolojik çalışmalar etiyolojinin İVK gelişiminde bir anomali olduğunu ortaya koymuştur $(4,5,6)$.
İliak arterde benzer bir anomali, retroiliak üreter gelişmesine neden olabilir (7).

$\mathrm{Bu}$ çalışmada, kliğimizde RÜ nedeniyle retrokaval segmentin eksizyonu yapılmadan açık cerrahi onarım ile üreteroüreteral anostomoz yaptığımız sekiz olgunun sonuçlarını bildirdik. Literatürde, tekmerkezde en fazla sayıda opere edilen hastanın bildirildiği ilk çalışmadır. İkinci büyük seri, Simforoosh ve arkadaşlarının laparoskopik pyelopyelostomi ile tedavi ettikleri altı olguluk seridir (8).

\section{HASTALAR ve METOD}

Mayıs 2005 ve Mayıs 2018 tarihleri arasında kliniğimizde RÜ tanısı ile opere edilen hasta 8 hasta çalışmaya dahil edildi. Tüm hastaların demografik verileri, başvuru yakınmaları, preoperatif görüntüleme yöntemleri, operasyon verileri, perioperatif ve postoperatif komplikasyon oranları, postoperatif kontrollerde saptanan verileri hasta dosyalarından kaydedildi ve değerlendirildi. Tüm hastaların bilgilendirilmiş onamı alındıktan sonra opere edildi.

\section{Hastalara uygulanan görüntüleme yöntemleri}

Hastalar preoperatif ve postoperatif dönemde üriner sistem ultrasonografi (USG), bilgisayarlı tomografi-ürografi (BTÜ) ve ${ }^{99 m}$ Tc-DMSA kortikal sintigrafı ve ${ }^{99 m}$ Tc-DTPA ile diüretikli dinamik renal sintigrafi ile değerlendirilmişti. Preoperatif dönemde USG'de ve/veya BTÜ'de obstrüktif hidronefrozdan şüphelenilen hastaların kesin tanısı için dinamik sintigrafi kullanıldı ve böbrek içindeki aktivitenin maksimum değerinin \%50'sine düşmesi için geçen süreyi ifade eden $\mathrm{T}^{1} \frac{1}{2}$ değerinin 20 dakika ve üzerinde olması obstrüksiyon lehine yorumlandı. Şekil 1, sağ RÜ tanılı bir hastanın BTÜ'sini göstermektedir ve sağ böbrek 
fonsiyonunun sola göre belirgin şekilde geciktiği ve să̆ hidronefroz, sağ proksimal üreterde dilatasyon, sonrasında üreterin vena kava posteriorundan mediale doğru kıvrılarak normal kalibrede seyri görülmektedir.

\section{Cerrahi teknik}

Genel endotrakeal anestezi indüksiyonundan sonra bir Foley kateter yerleştirildi. Hastaya 90 derece lombotomi pozisyonu verildi. Düşük lombotomi kesi yapıld1. Periton medialize edildikten sonra, dilate proksimal üreter görüldü ve askıya alındı (Şekil 2). Üreter diseke edildi ve vena kavanın anteriorundan medialine kıvrıldığ görüldü ve distal kısım da askıya alındı (Şekil 3). Ardından proksimal üreter vena kavanın anterioruna döndüğü yerden tam kat kesildi. Üreter içerisine 6 Fr double-j kateter yerleştirildi. Üreter spatüle edilerek 4-0 vicryl sütür ile gerilimsiz üreteroüreteral anostomoz yapıldı (Şekil 4). Anostomoz bölgesine yakın bir bölgeye 1 adet Jackson-Pratt $^{\circledR}$ dren yerleştirildi. Double-J stent 4 hafta sonra çıkarıldı. Operasyondan 3 ay sonra ${ }^{99 \mathrm{~m}}$ Tc-DTPA diüretik renogram ve boşaltımsal ürogram yapıldı. Operasyonlar, bir üniversite hastanesinde uygulanmış olup, bu konuda ehil farklı cerrahların yer aldığı ekipler tarafindan gerçekleştirilmiştir.

\section{Ístatistiksel analiz}

Kategorik ölçümler sayı ve yüzde olarak kaydedilirken, sürekli ölçümler ortalama ve minimum-maksimum olarak kaydedildi. Preoperatif ve postoperatif değerler arasındaki sürekli ölçümlerin karşılaştırılmasında MannWhitney U testi kullanıldı. İstatistiksel analiz için SPSS 22.0 kullanıldı. P değerinin 0.05 'den küçük değerleri, istatistiksel olarak anlamlı kabul edildi.

\section{BULGULAR}

Sekiz hastanın 5'i erkekti ve ortalama yaşları 36.2 yıldı (25-48). Ortalama vücut kitle indeksleri (VKİ) $23.4 \mathrm{~kg} / \mathrm{m}^{2}$ ydi. Ortalama operasyon süresi 64 dakikaydı (58-92). Hastaların \%75'inde başvuru yakınması yan ağrısıydı. Preoperatif ortalama kreatinin değeri $1.16 \mathrm{mg} / \mathrm{dL}$ 'ydi. Ortalama hospitalizasyon süresi 2.32 gün ve Foley sonda süresi 1.08 gündü. İki hastada postoperatif dönemde yüksek ateş nedeniyle hospitalizasyon gerekliliği oldu ve bu hastalar uygun antibiyoterapi ile tedavi edildiler. Hastaların demografik verileri ve perioperatif verileri, Tablo 1'de özetlenmiştir.

Tüm hastaların preoperatif USG'si mevcuttu ve 5 hastanın BTÜ'si mevcuttu. Postoperatif dönemde tüm hastaların kontrol görüntülemesi BTÜ ve nükleer tıp çalışması ile yapıldı. Hastaların preoperatif ve postoperatif statik sintigrafileri arasında istatistiksel anlamlı bir ilişki yoktu ancak, dinamik renal sintigrafi farklılığ 1 anlamlıyd 1 (sirasıyla, $p=0.741$ ve $\mathrm{p}=0.016$ ). hastaların preoperatif ortalama $\mathrm{T}^{1} / 2$ değeri $25.7 \mathrm{dk}$, postoperatif ortalama $\mathrm{T}^{1} \frac{1}{2}$ değeri ise $14.4 \mathrm{dk}$ 'ydı. Hastaların preoperatif ve postoperatif dönemdeki görüntüleme yöntemleri ve bulguların karşılaştırılması, Tablo 2'de özetlenmiştir.

\section{TARTIŞMA}

İlk RÜ vakası, 1893'de Hochstetter tarafından tanımlanmıştır (9). Anomali, çoğunlukla sağ üreteri ilgilendirir, eğer sol üreteri kapsarsa sıklıkla parsiyel veya komplet situs inversus veya inferior vena kava duplikasyonu ile birliktedir (10). RÜ insidans1 $1 / 1000$ canl1 doğumdur $(11,12)$. Hastalar genellikle yaşamın üçüncü-dördüncü dekadında tanı alır. Erkeklerde kadınlardan 3 kat daha sık görülür. Hastalar genellikle sağ yan ağrısı ile başvururlar, ancak idrar yolu enfeksiyonları, 
hematüri veya ürolitiyazis ile de başvurular görülebilir (13). Çalışmamızda, literatürle uyumlu olarak RÜ saptanan olguların çoğu erkekti. En sik başvuru yakınması yan ağrısıydı ve vakaların tamamında RÜ sağ taraftaydi.

RÜ anomalisinde üreter, tipik olarak inferior vena kavanın posteromedialine deviye olur, etrafını sarar ve önüne geçerek normal bir seyir kazanmak için medialden lateral doğru yer değiştirir ve distalde mesaneye doğru yol alır. Renal pelvis ve vena kavayı geçene kadar olan üreter kısmı tipik olarak elonge ve dilatedir. Hastalara genellikle üreter obstrüksiyonunun neden olduğu hidronefroza bağlı aralıklı veya devamlı flank veya abdominal ağrı ile başvurur. Bazı hastalarda rekürren idrar yolu enfeksiyonu ve hematüri görülebilir. Tabloya renal kalküli ve piyonefroz eşlik etmesi, durumu komplike hale getirebilir. Bazı vakalar, diğer patolojilere yönelik yapılan radyolojik incelemelerde insidental olarak tanı alabilir.

RÜ, iki klinik tipte kategorize edilmektedir. Tip 1, en sik görülen tipdir ve vakaların yaklaşık \%50'sinde orta-ciddi hidronefroza neden olur. Üreteral segmentin medial deviasyonu ileri düzeydedir ve üreterde $\mathrm{S}$ veya "balık-oltası" şeklinde deformite görülür. Tip 2'de üreterin medial deviasyonu daha az düzeydedir, hidronefroz yoktur veya 1lımlıdır ve hastaların yaklaşık \%10'unda görülür (14). Spiral BT ve manyetik rezonans görüntüleme en iyi tanı araçlarıdır. Obstrüktif dilatasyonu konfirme etmek için önerilen tetkik, diüretikli dinamik renal sintigrafidir. Semptomlar geliştiğinde veya fonksiyonel olarak anlamlı obstrüksiyon mevcut olduğunda, cerrahi onarım endikedir. Cerrahi tedavi, siklıkla semptomatik olarak prezente olan tip 1 vakalar için tercih edilmektedir. Preve postoperatif dönemde tüm hastalarda statik ve dinamik sintigrafiyi uyguladık ve dinamik sintigrafideki anlamlı değişiklik, obstrüksiyonun giderildiğini doğruladı. Ayrıca, postoperatif tüm hastalarda BTÜ ile, tedavi başarısını anatomik olarak da konfirme ettik.

Abdominal ultrasonografi ile hidronefroz tanıs1 konabilir. Ancak üreter bütünlügünü ve komşu organları da değerlendirmek ve hidronefrozun etyolojisini ortaya koyabilmek için opaklı görüntüleme yöntemine başvurmak, bu anomalinin tanısını koyabilmek için ideal yaklaşımdır. Geçmişte sıklıkla kullanılan retrograd üreteropiyelogram, invaziv bir yöntem olması ve hastalar tarafindan toleransinın az olması nedeniyle günümüzde neredeyse tamemen bırakılmıştır. Bunun yerine daha hizlı ve doğru tanı koymaya yardımcı bir görüntüleme yöntemi olan BTÜ, sıklıkla kullanılmaktadır. Manyetik rezonans ürografi (MRÜ) de radyasyon içermeme avantaj1 ile uygun hastalarda BTÜ'ye bir alternatif olarak kullanılabilir. Önemli ayırıcı tanılar retroperitoneal fibrozis ve üreterlerin lokalizasyonlarını değiştiren retroperitoneal kitlelerdir. Abdominopelvik BT ve MR, ayırıcı tanı ve doğru tanıya gidebilmek için oldukça yardımcıdır.

RÜ tedavisi, anomalinin cerrahi olarak düzeltilmesidir. Amaç, üreterin kesilerek vena kavanın önünde, normal anatomisine uygun biçimde tekrar konumlandırılmasıdır. Bunun için bir double j kılavuzluğunda renal pelvis ve üreter arasında veya üretero-üreteral anastomoz uygulanabilir. İnferior vena kavanın arkasında kalan ve aperistaltik olabilen üreter segmenti eksize edilebilir veya bırakılabilir. Bizim vakalarımızda segmentler bırakıldı. Semptomatik vakalarda cerrahi tedavi uygundur. Minimal hidronefrozu olan ve belirgin semptomu olmayan hastalar takip edilebilir. RÜ onarımı açık, laparoskopik veya robotik yöntemle uygulanabilir. Laparoskopik ve robotik yöntemlerin, kısa hospitalizasyon süresi, erken iyileşme, daha az postoperatif ağrı ve daha iyi kozmetik sonuçlar gibi avantajları vardır $(15,16)$. Ancak, önemli olan cerrahın en tecrübeli olduğu teknikle işlemi gerçekleştirmesidir. Bazı gruplar, bu konjenital anomaliyi düzeltmek için laparoskopik 
üreteroüreterostomi veya pyeloureterostomiyi tanımlamıştır. $\mathrm{Bu}$ anomalinin laparoskopik onarımında transperitoneal ve retroperitoneal yaklaşımlar bildirilmiştir. Transperitoneal üreteroüreterostominin önemli bir dezavantajının daha uzun operasyon süresi olduğu farklı serilerde vurgulanmıştır $(17,18)$, ancak retroperitoneal yönteme göre intrakorporeal sütürasyonun daha kolay ve daha az zaman aldığ 1 da belirtilmiştir (19). Laparoskopik serilerde bildirilen en kısa operasyon süresi 3.5 saattir (20). Diğer serilerde 3.75 saat ile 9.3 saat arasında değişen süreler bildirilmiştir. Transekte edilen üreterin devamlı sütürasyon ile re-anastomuzunun ve double-j stentin intraoperatif yerleştirilmesinin operasyon süresini kısaltacağı vurgulanmıştır (8). Biz vakalarımızda açık cerrahiyi uyguladık. Ortalama operasyon süremizin literatürde bildirilen sürelerden çok daha kısa olmasının en önemli nedenleri açık cerrahi yöntem ve stentin intraoperatif yerleştirilmesiydi. Preoperatif dönemde stent olan hastalarda da enfektif komplikasyonları önlemek için mutlaka operasyon sırasında yeni stent ile değiştirdik.

Retrokaval segmentin rezeksiyonu tartışmalı bir konudur. Birçok çalışmada bu segment eksize edilmiştir. Ancak segmentin anormal görünüşte, dar ve displastik olmaması durumunda eksizyonuna gerek duymayan otörler de mevcuttur (8). Biz, farklı olarak bu segmentin proksimal ve distalinden tam kat kesi ile üreteri vena kavanın anterioruna alarak, re-anostomoz uyguladik. Retrokaval segmentin diseksiyonu sırasında vena kavanın lasere olma riski ve üreteroüreteral anastomoz için yeterli uzunlukta üreter segmentinin olması, bu kararda belirleyici olmuştur.

Çalışmamızın retrospektif yapısı ve karşılaştırmalı bir grubun (laparoskopi, robotik, vs.) olmaması kısıtlı yönleridir. Ancak literatürde, nadir görülen bu konjenital anomalinin tedavi sonuçlarının sunulduğu en çok vaka sayılı çalışmalardan birisi olması nedeniyle önemli olduğunu düşünmekteyiz.

\section{SONUÇ}

RÜ, genellikle üçüncü veya dördüncü dekadda neden olduğu semptomlarla tanı konan oldukça nadir görülen ancak önemli bir konjenital anomalidir. Tedavisi, anomalinin cerrahi olarak düzeltilerek semptomların giderilmesi ve komplikasyonların önlenmesidir. Tedavi yöntemi olarak cerrahın tecrübesi ve hastanın tercihi belirleyici faktörlerdir.

Çıkar Çatışması: Yok 
Tablo 1. Hastaların demografik verileri ve perioperatif veriler

\begin{tabular}{|c|c|}
\hline Değişkenler & Değer $^{1}$ \\
\hline \multicolumn{2}{|l|}{ Cinsiyet } \\
\hline Kadın & $3(38)$ \\
\hline Erkek & $5(62)$ \\
\hline Yaş (Yıl) & $36.2(25-48)$ \\
\hline Vücut kitle indeksi $\left(\mathrm{kg} / \mathrm{m}^{2}\right)$ & $23.4(18.2-33.9)$ \\
\hline \multicolumn{2}{|l|}{ Retrokaval üreter tarafı } \\
\hline Să̆ & $8(100)$ \\
\hline Sol & - \\
\hline \multicolumn{2}{|l|}{ Başvuru yakınması } \\
\hline Yan ağrisı & $6(75)$ \\
\hline Piyelonefrit & $2(25)$ \\
\hline Preoperatif kreatinin değeri (mg/dL) & $1.16(0.89-1.21)$ \\
\hline \multicolumn{2}{|l|}{ Preoperatif double-j stent varlığı } \\
\hline Var & $2(25)$ \\
\hline Yok & $6(75)$ \\
\hline Operasyon süresi (dk) & $64(58-92)$ \\
\hline Hospitalizasyon süresi & $2.32(1-4)$ \\
\hline Foley sonda süresi & $1.08(1-3)$ \\
\hline Double-j stent süresi (gün) & $29.8(28-34.6)$ \\
\hline \multicolumn{2}{|l|}{ Perioperatif komplikasyonlar } \\
\hline Hemoraji (>200 ml kan kaybı) & - \\
\hline İleus & - \\
\hline Enfeksiyon & $2(25)$ \\
\hline Uzamış idrar drenajı & - \\
\hline
\end{tabular}

Tablo 2. Hastalara preoperatif ve postoperatif dönemde uygulanan görüntüleme yöntemleri ve karşılaştırılması

\begin{tabular}{lccccc}
\hline Görüntüleme yöntemi & \multicolumn{2}{c}{ Preoperatif uygulama } & \multicolumn{2}{c}{ Postoperatif uygulama } & P değeri $^{\mathbf{1}}$ \\
\hline & Uygulama sayısı & Değer $^{2}$ & Uygulama sayısı $^{2}$ & Değer $^{2}$ & \\
\hline Üriner sistem USG $^{3}$ & 8 & - & - & - & - \\
\hline BTÜ $^{4}$ & 5 & - & 8 & - & - \\
\hline $\begin{array}{l}\text { 99me-DMSA }^{5} \text { kortikal } \\
\text { sintigrafı }\end{array}$ & 8 & $41(32-49)$ & 8 & $48(34-54)$ & 0.741 \\
\hline $\begin{array}{l}\text { 99m-DTPA } \\
\text { dinamik sintigrafi }\end{array}$ & 8 & $25.7(22.1-30.9)$ & 8 & $14.4(10.2-17.3)$ & $\mathbf{0 . 0 1 6}$ \\
\hline
\end{tabular}

${ }^{1}$ İstatistiksel anlamlı $\mathrm{p}$ değerleri bold ve italik verilmiştir

${ }^{299 m}$ Tc-DMSA kortikal sintigrafi için diferansiyel fonksiyonlar, ${ }^{99 m}$ Tc-DTPA diüretikli dinamik renal sintigrafi için $\mathrm{T}^{1 / 2}$

değeri (dk) baz alınmıştır

${ }^{3}$ Ultrasonografi

${ }^{4}$ Bilgisayarlı tomografi-ürografi

${ }^{5}$ Teknesyum-99m dimerkaptosüksinik asit

${ }^{6}$ Teknesyum-99m dietilentriaminepentaasetik asit 

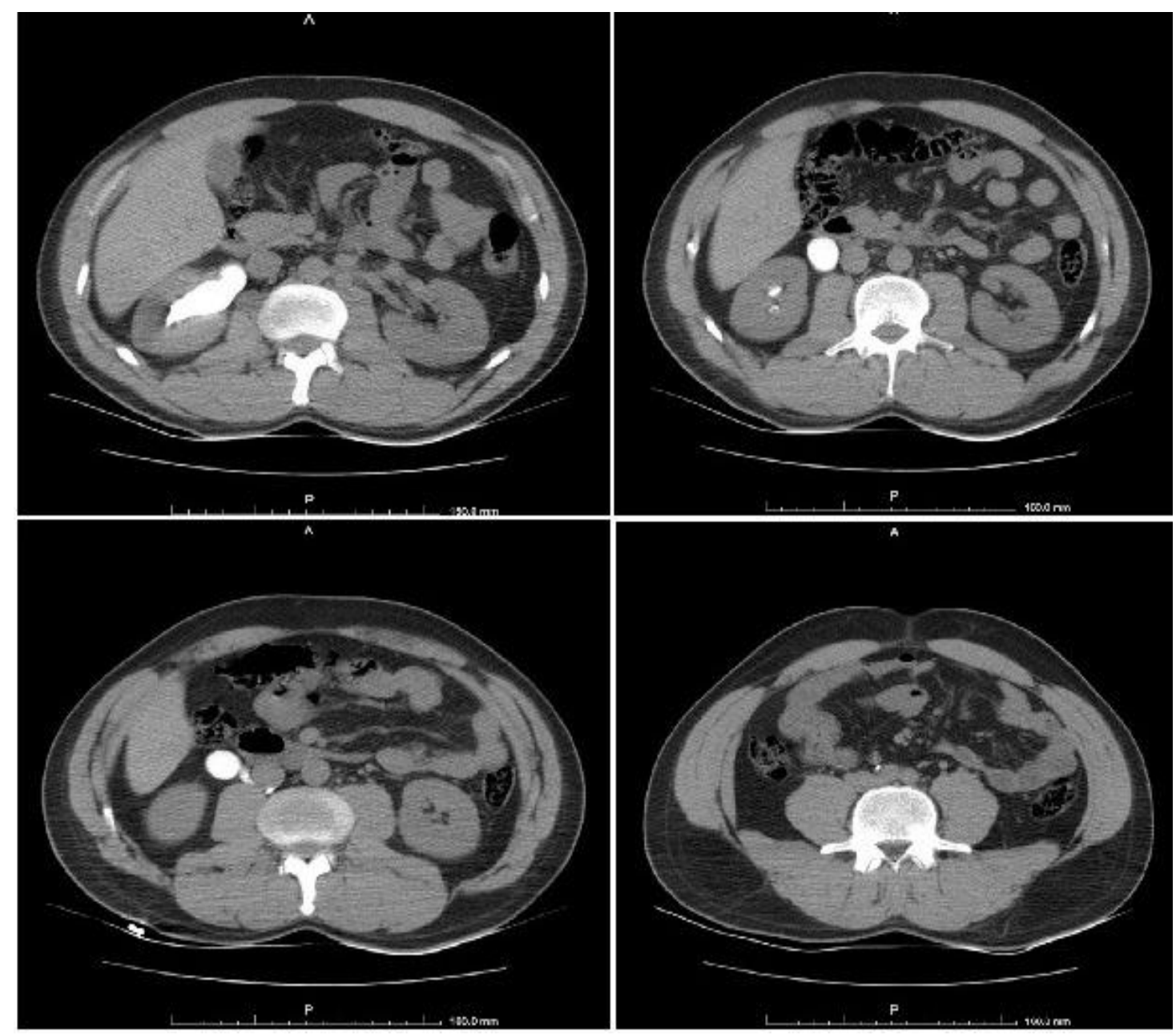

Şekil 1. Sağ retrokaval üreter anomalisinin bilgisayarlı tomografi-ürografi görüntüleri

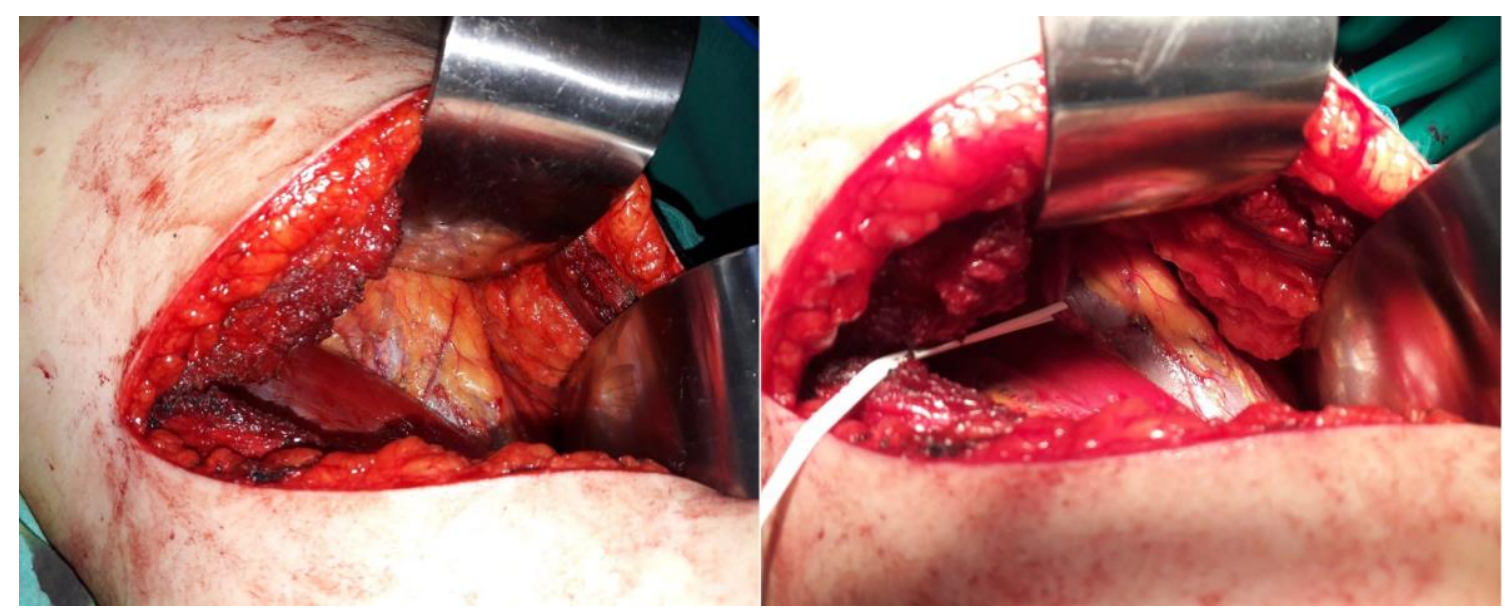

Şekil 2. Sağ düşük lombotomi kesi sonrasında dilate proksimal üreterin askıya alınması 


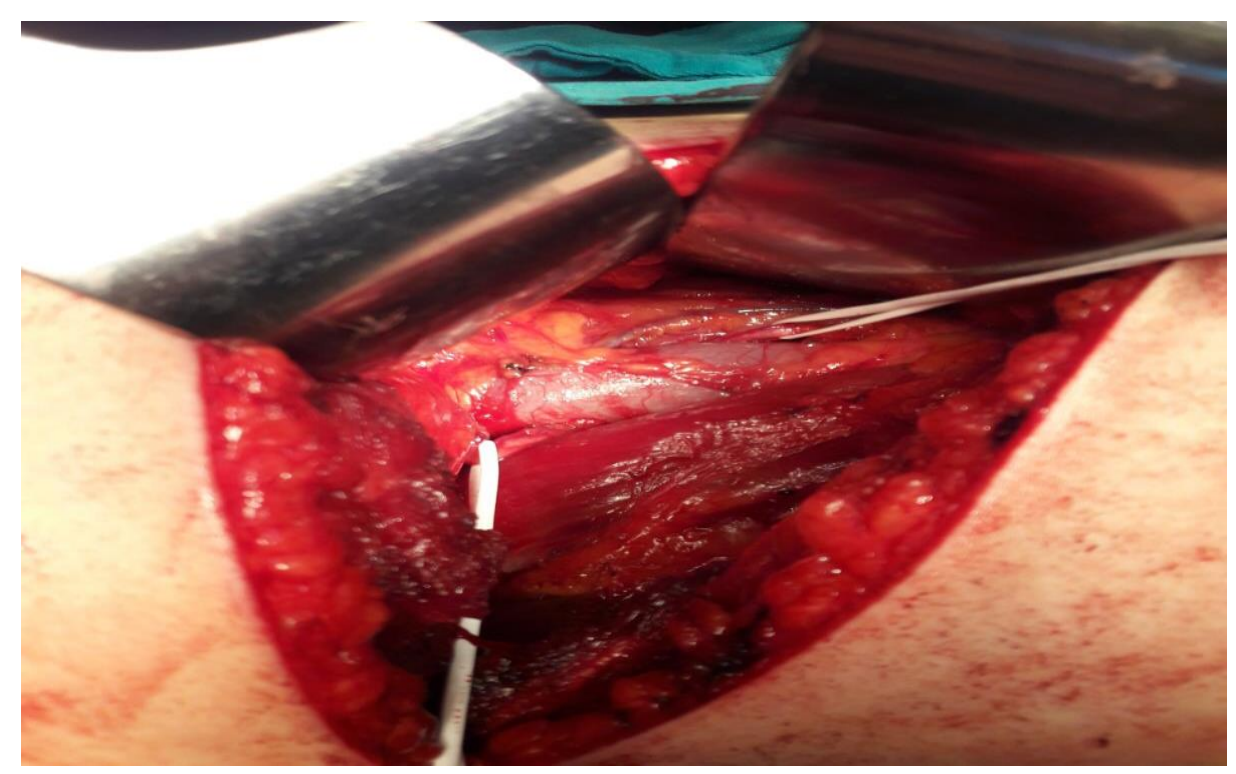

Şekil 3. Üreterin inferior vena kavanın proksimal ve distalinden askıya alınması

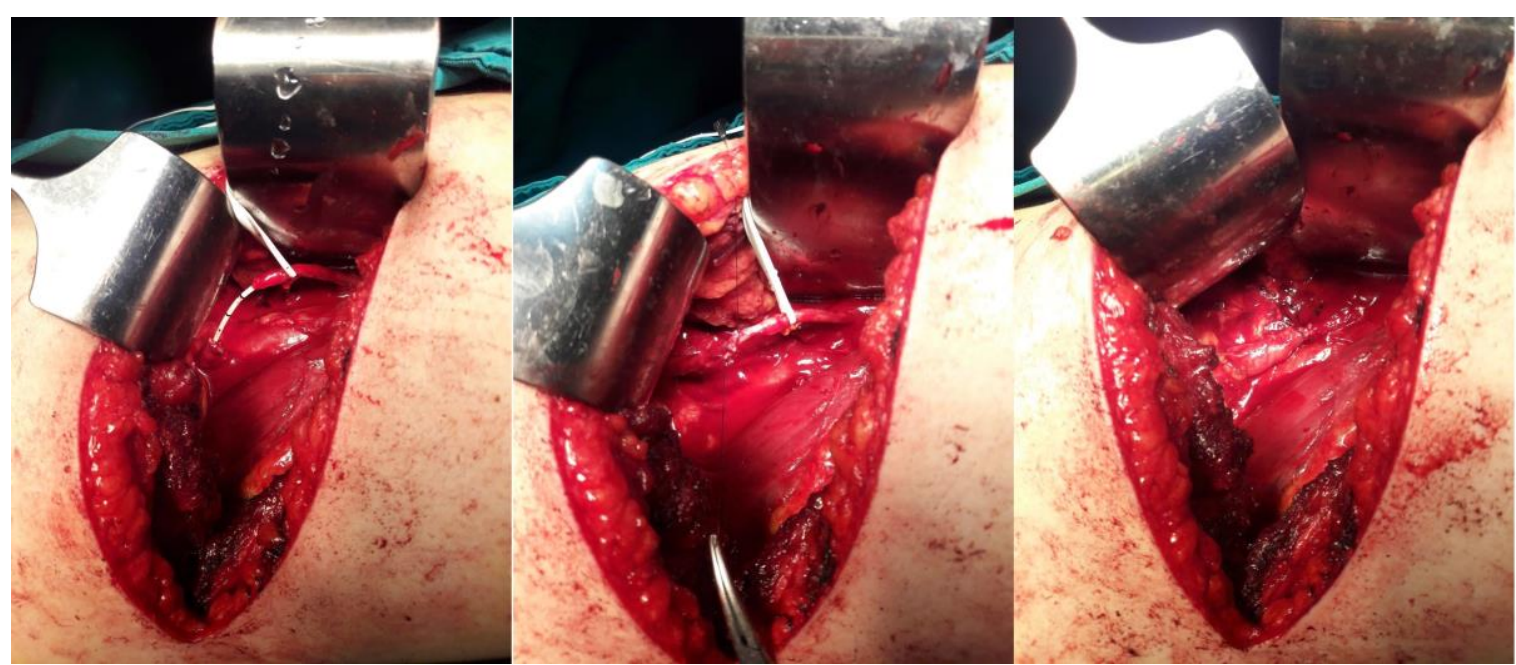

Şekil 4. Üreterin içerisinde double j görüntüsü ve 4-0 vicryl sütür ile çepeçevre, gerilimsiz üreteroüreteral anastomoz 


\section{REFERANSLAR}

1. Harrill HC. Retrocaval Ureter: Report or a Case with Operative Correction of the Defect. The Journal of Urology 1940;44:450-457.

2. Heslin JE, Mamonas C. Retrocaval ureter: report of four cases and review of literature. J Urol 1951;65:212-222.

3. Peters C, Schlussel R, Mendelson C. Preureteral Vena Cava. Campbell-Walsh Urology, El-Sevier Saunders, Philadelphia 2012:3263-3265.

4. Schlussel R, Retik A. Preureteral Vena Cava. Campbell-Walsh Urology 9th ed Elsevier Saunders 2007:3418-3420.

5. Lesma A, Bocciardi A, Rigatti P. Circumcaval ureter: embryology. european urology supplements 2006;5:444-448.

6. Chuang VP, Mena CE, Hoskins PA. Congenital anomalies of the inferior vena cava. Review of embryogenesis and presentation of a simplified classification. The British journal of radiology 1974;47:206-213.

7. Anderson JK. Surgical anatomy of the retroperitoneum, adrenal, kidneys, and ureters. Campbell-Walsh Urology ninth edition 2007:25-28.

8. Simforoosh N, Nouri-Mahdavi K, Tabibi A. Laparoscopic pyelopyelostomy for retrocaval ureter without excision of the retrocaval segment: first report of 6 cases. J Urol 2006;175:2166-2169; discussion 2169.

9. Olson RO, Austen Jr G. Postcaval Ureter: Report and Discussion of a Case with Successful Surgical Repair. N Engl J Med 1950;242:963-968.

10. Rubinstein I, Cavalcanti AG, Canalini AF, Freitas MA, Accioly PM. Left retrocaval ureter associated with inferior vena caval duplication. The Journal of urology 1999;162:1373-1374.

11. Sener RN. Nonobstructive right circumcaval ureter associated with double inferior vena cava. Urology 1993;41:356-360.

12. Chou CT, Yang AD, Hong YC, Wu HK. Bilateral retrocaval ureters with IVC duplication. Abdom Imaging 2006;31:596-597.

13. Gulmi FA, Felsen D, Vaughan E. Pathophysiology of urinary tract obstruction. Smith's textbook of endourology, Wiley-Blackwell, West Sussex (United Kingdom), 2012, pp. 95-119.

14. Bateson EM, Atkinson D. Circumcaval ureter: a new classification. Clin Radiol 1969;20:173-177.

15. Bhandarkar D, Lalmalani J, Shivde S. Laparoscopic ureterolysis and reconstruction of a retrocaval ureter. Surgical Endoscopy And Other Interventional Techniques 2003;17:1851-1852.

16. Tobias-Machado M, Lasmar MT, Wroclawski ER. Retroperitoneoscopic surgery with extracorporeal uretero-ureteral anastomosis for treating retrocaval ureter. International braz j urol 2005;31:147-150.

17. Polascik TJ, Chen RN. Laparoscopic ureteroureterostomy for retrocaval ureter. J Urol 1998;160:121-122.

18. Salomon L, Hoznek A, Balian C, Gasman D, Chopin DK, Abbou CC. Retroperitoneal laparoscopy of a retrocaval ureter. Bju Int 1999;84:181-182.

19. Ramalingam M, Selvarajan K. Laparoscopic transperitoneal repair of retrocaval ureter: report of two cases. J Endourol 2003;17:85-87.

20. Gupta NP, Hemal AK, Singh I, Khaitan A. Retroperitoneoscopic ureterolysis and reconstruction of retrocaval ureter. J Endourol 2001;15:291-293. 